\title{
ROLF BREIDENBACH
}

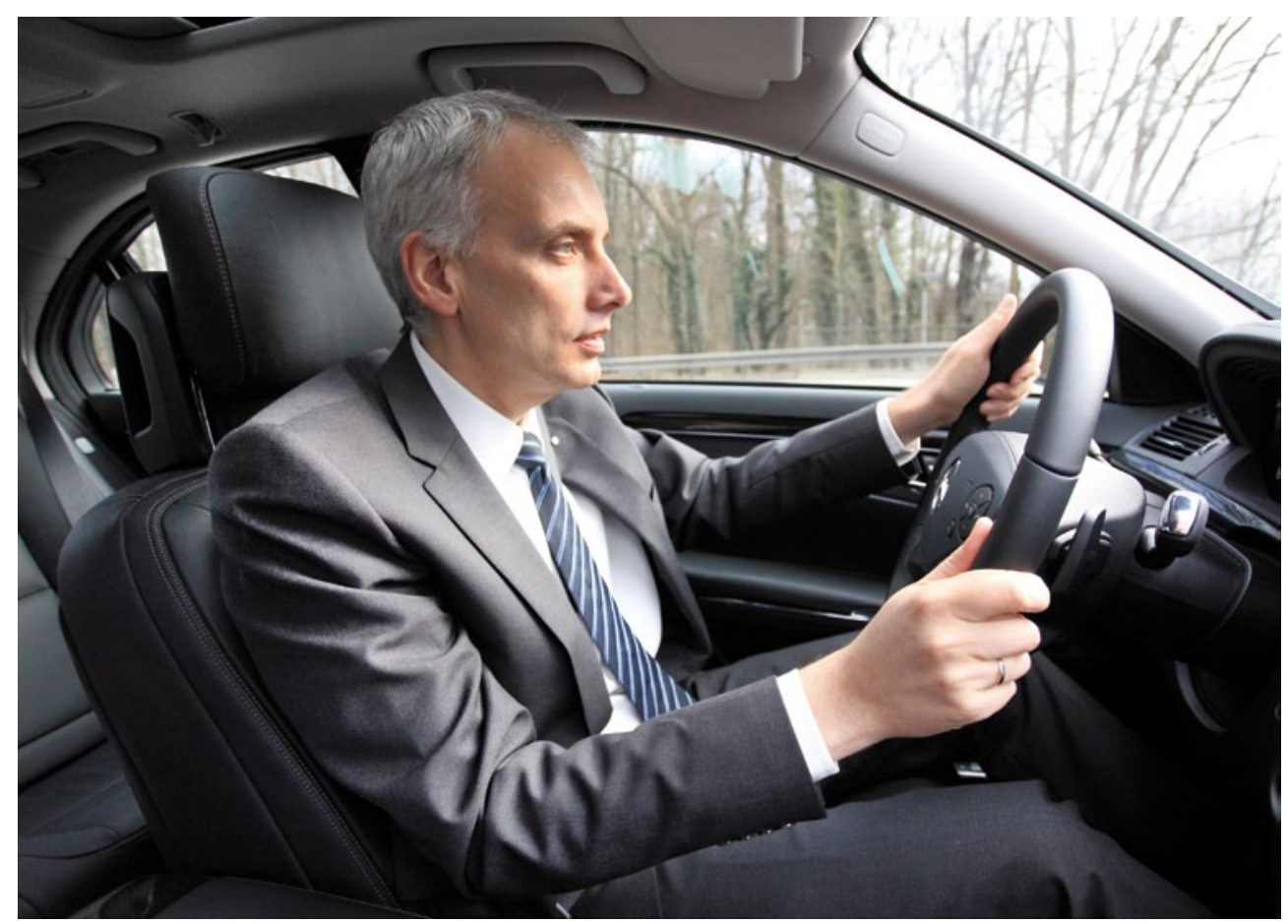

Leuchtende Augen bekommt Dr. Rolf Breidenbach, Vorsitzender der Geschäftsführung des Automobilzulieferers Hella KGaA Hueck \& Co. im westfälischen Lippstadt, wenn er von der LED-Technik und deren Möglichkeiten für die Entwicklung der Automobilbeleuchtung in den nächsten zehn Jahren spricht. Im Hella-Krisenjahr 2004 eingestiegen, meldet der erste nicht aus der Eigentümerfamilie stammende Manager glänzende Ergebnisse. Erfolg hat er und kombiniert diesen mit einer ordentlichen Portion Witz und Sympathie.

BILD (C) Hella

\section{„HELLA UND BORUSSIA DORTMUND“}

Was eint Hella mit Borussia Dortmund? Beide haben eine mehr als 100-jährige Tradition. Hella wurde 1899 gegründet, die Borussia 1909. Beide hatten gute Zeiten - und weniger gute. Beide haben Trainer, die aus Mannschaften Teams formten - Erfolgsteams. Hella steht mit $15 \%$ Weltmarktanteil derzeit auf Platz 3 der europäischen Beleuchtungshersteller im Automobilsektor, die Borussia derzeit (Stand: 14. März 2012) auf Platz 1 der Bundesliga. Das ist Motivation, für Breidenbach und Hella. Zu Studentenzeiten an der RWTH Aachen stand er in der Südkurve des damaligen Westfalen-Stadions. Dort brodelt's und kocht's. Auch heute noch versucht er keines der Borussen-Heimspiele zu verpassen. Inzwischen als erfolgreicher Manager mit Frau, drei Kindern und Dauerkarte. Auch Untergründe mit wenig $\mu$ meistert der Dr.-Ing. mit Bravour. Das hat Vorteile - beim Hobby Skifahren genauso wie bei Preisverhandlungen mit Kunden.

\section{„BREIDENBACH UND KLOPP“}

Was zählt ist auf dem Platz. Auch wenn der Platz unterschiedlich ist, die Leidenschaft ist dieselbe. „Kloppo“ fiebert und brüllt am Spielfeldrand. Breidenbach ist ruhig, souverän, überlegt und wirkt besonnen. Intensität spürt man beim heute 48-jährigen ehemaligen McKinsey-Mann, wenn er Hellas Netzwerkstrategie erläutert. Neueste Pakete, Prozesse, Technik aus Leitwerken in die auf der ganzen Welt liegenden Fertigungsstätten zu transferieren. Ausdauer und Durchsetzungskraft spürt man, wenn er von den Krisenjahren, den daraus resultierenden Adaptionsprozessen und Hellas Wachstumsstrategie in China und Indien spricht.

Feuer versprüht der gebürtige Bochumer und leidenschaftliche Teamplayer, wenn er von den wirtschaftlichen Erfolgen Hellas oder den Wachstumstreibern des Unternehmens schwärmt. Die nächsten zehn Jahre wird das Unternehmen den Megatrend Umwelt und die Reduzierung von $\mathrm{CO}_{2}$-Emissionen über effizientes Energiemanagement fördern. Den anderen Megatrend Sicherheit bedienen die Lippstädter mit aktiven und passiven Sicherheitssystemen, adaptiven Beleuchtungsmodulen oder Abstandswarnern. Und der neue Megatrend LED wird die Automobilbeleuchtung evolutionieren. Für 2020 liest Breidenbach einen Durchdringungsgrad für LED-Beleuchtung von $70 \%$ der weltweit gebauten Fahrzeuge aus der Glaskugel. Von den Superluxusfahrzeugen bis zur Economy-Class.

Und jetzt sind wir beim großen Unterschied zum Fußball. Wer dann beim Auto günstig kauft, fährt trotzdem mit „Weitblick“, sicher und trocken. Wer beim Fußball günstig kauft, steht sich oft die Füße in den Bauch und manchmal auch im Regen.

Man nimmt Breidenbach gern ab, wenn er sagt: „Ich bin mit Begeisterung und dem Herzen Vorsitzender der Geschäftsführung, das Unternehmen entwickelt sich ausgezeichnet. Es macht mir Freude und gibt mir Befriedigung, Hella gemeinsam mit Dr. Jürgen Behrend (Redaktion: Geschäftsführender, persönlich haftender Gesellschafter) weiter zu entwickeln.“ 